\title{
Sustaining Hegemony: Educational Use of Photographs Representing Human Distress
}

\section{PAULA ALEXANDRA AMBROSSI}

The use of photography representing human distress in higher education warrants moral attention, owing to the imperative that we avoid objectifying the vulnerable communities who are often represented in those images. Assuming the fundamental Kantian precept that we should always treat others as ends and never merely as means, I extend this precept to include the photographic representation of human distress which involves vulnerable others. This I explore by drawing on the critical theory of Horkheimer and the critical pedagogy of Gottesman. The tendency to decontextualise and depoliticise the act of 'using' photographs freely available in the public domain serves to consolidate the status quo and sustain the existing hegemony that allows such use and guides our moral judgements. Derrida, I suggest towards the end of my paper, has some illuminating things to say about this.

But the world might guess it; and I will not bare my soul to their shallow, prying eyes. My heart shall never be put under their microscope. There is too much of myself in the thing (Oscar Wilde, 1891).

\section{INTRODUCTION}

The use of photographic resources used for educational purposes warrants moral attention, especially those photographs which represent human distress owing to the imperative that we avoid objectifying the vulnerable communities who are often represented in those images.

My interest in this paper is in the secondary, rather than in the primary use of such images, available in educational contexts, particularly in higher education. By secondary use I mean usage which differs from the one originally intended. A central assumption around 'usage' here is that we are required to abide by the fundamental Kantian precept that we should always treat others as ends and never merely as means, and I extend this precept to include the photographic representation of human distress which involves vulnerable others.

I begin with a brief discussion on how philosophers treat the subject of photographs representing human distress, before moving on to consider how these images come to be commonly used and re-used. The instrumentalisation of ordinary images is not necessarily objectionable, but it often creates the complacency that follows habit - the habit of uncritically sharing and using images that we find in print, 
social and other media, leading to the potential objectification of those represented in images involving human distress.

I explore objectification by drawing on the critical theory of Horkheimer (1975) and the critical pedagogy of Gottesman (2016). I argue that, whilst it is common to view a photograph as something we simply 'see' or 'analyse' as a visual image, the act of 'using' these images can be treacherous. The way we 'use' an image is part of a social and political narrative, which the user and seer may be unaware of or which may be hidden from her. A second argument is that the tendency to decontextualise and depoliticise the act of 'using' photographs serves to consolidate the status quo and sustain the existing hegemony that allows such use. This second argument includes the view that a decontextualised, depoliticised account of seeing images of human distress can lead to an erroneous and superficial construction of the 'other', as represented here by members of vulnerable communities. ${ }^{1}$ Derrida, I suggest towards the end of my paper, has some illuminating things to say about this.

To explore my thesis, I will consider two examples of the use of images representing human distress: an exhibition of Bourdieu's photographs of Algeria and a photograph of the burnt-out Grenfell tower ${ }^{2}$ in London during a lecture. The first provides an example of the use of images representing events which are geographically and temporally distant, presented in the context of a public exhibition organised by Goldsmiths, University of London; the second provides an example of an image of a recent tragedy involving human loss, presented in the context of a lecture.

\section{FROM OBJECTS OF USE TO OBJECTS OF ABUSE}

The moral and ethical considerations of the secondary use of photographic images have been mostly left unexplored by philosophers. The ethics of visual research on the other hand, particularly in journalism (Langmann and Pick, 2014), medicine (Berle, 2008; Csengei 2003) and ethnography (Back, 2009) which focuses on how images may be used for research has received much attention. Some of this use has been secondary (secondary data), but seldom receives a philosophical treatment. The necessary institutional ethical requirements for research often turn ethical considerations into a kind of exercise with little room or encouragement for philosophical reflection (Small, 2001).

Philosophy of photography not related to the arts is fairly recent (Azoulay, 2010; Roberts, 2013), and mostly focuses on the primary use of images, involving the photographer, the subject and the viewer. Of these, philosophical debates on images representing human distress have addressed various aspects of primary use. Moore (2006) for instance, highlights some: what counts as such an image; how certain images become iconic; what they can and cannot tell us; how they represent the world; their contextualisation in historical or political terms; and the response and responsibility they invoke. In this last respect, Sontag (2003) and Butler (2007) are some of the authors who have contributed in ways I touch upon. Hallander (2015) addresses secondary use to an extent while considering the testimonial representation of suffering in education, for instance when teaching about the Holocaust. This, however, would not constitute secondary use in the sense I mean, but would rather be a repetition of a primary use: informing audiences about the events represented in the image. A secondary element would be Hållander's encouragement to 'hack into' the socio-political aspects of the photographs in order to see what has been left out, why and how. 
When we contemplate using an image we must consider what the photograph once stood, currently stands, or can novelly stand for (Azoulay, 2010). Photographs can be sorted according to not just the original intention of their creator, the subject or the context, but can be relocated 'within a spectrum of possible uses that are not necessarily subjugated to the existence of a photograph. Something about the limitation of this kind of use is exposed in every renewed viewing of photographs, revealing that which our use of the photograph did not let us see when we first viewed it' (Azoulay, 2010, p. 9). She adds, 'Even if one of these protagonists-usually the photographer-enjoys a privileged position and is the one responsible for setting the boundaries of the photograph, s/he alone does not determine what will be inscribed in the frame and what might be reconstructed from it regarding the situation photographed' (p. 11). This is particularly relevant when the photographers are neither artists nor journalists but members of the public who take and upload photographs with little thought or sense of 'placing any boundaries' or responsibility towards the subjects and future viewers. This is starkly exemplified in non-human photography (remote sensor cameras, CCTV, etc.) with the multiple angles in space and time taken of an event and unsuspecting world, turning photographs (not photography) into a form of practice as opposed to remaining objects of use (Zylinska, 2015). This muddles the nature of what Azoulay called the 'protagonists' in the image, but not completely. A 'protagonist' Azoulay claims, are all those who have the agency to 'construct' the photograph: the photographer, the archivist and the spectator. In the current use of images however, it seems difficult to draw the line between the roles of 'archivist', 'spectator' and of 'author' of new meaning, and the photograph itself can come to be a protagonist as opposed to Azoulay's claim of it being an artefact in relation to the protagonists: 'the outcome of an encounter between several protagonists that might take on various forms' (p. 11). I argue that, unlike the postman image below, photographs representing human distress can become protagonists due to their social and political charge, and are therefore not so open to taking on various forms without becoming part of a potentially objectifying practice.

What bears a direct relation to whether we can say that the subject has been objectified or not, is whether the narrative surrounding the image treats its subject as ends or merely as means, thus becoming potential objects of abuse. The difference between a photograph as 'means' rather than as 'ends' is not always clear. All images can be a form of means, a point of departure to exemplify or signify something or someone. Images have been referred to in the literature as signifiers (Ahn, 2017; Grønstad and Gustafsso, 2012; Sontag, 2003; Sten et al., 2014; Reinhardt, 2012), so the question is whether our discourse relates, a) to the signified as an end in itself or b) to something else entirely: a means. I make the following distinction for the purpose of this argument: a photograph is used as 'ends' when the action and narrative surrounding it centres on the particular represented subject (Brink, 2000) (i.e. news, personal photographs of people or places we love, etc.). The same photographs would be used merely as means when the action or narrative enframing them refers to something other than the represented subject (Ahn, 2017) (i.e. utilised or consumed: images in ads, backgrounds, references, manuals, etc.).

Conflict can arise when an image that was primarily used as 'ends' is subsequently used merely as means. For instance, in social media, primary use of photographs representing persons, objects or events that have high significance to the author and are therefore used as 'ends' (i.e. a signifier of close intimacy), can be distributed indiscriminately in a secondary use, merely as means to a different message entirely, like in pornography, revenge, extortion, etc. (Chalfen, 2009). Less 
problematic is when a significant object of affection (someone's dog) becomes someone else's mere means to exemplify the concept of 'dogs' in general.

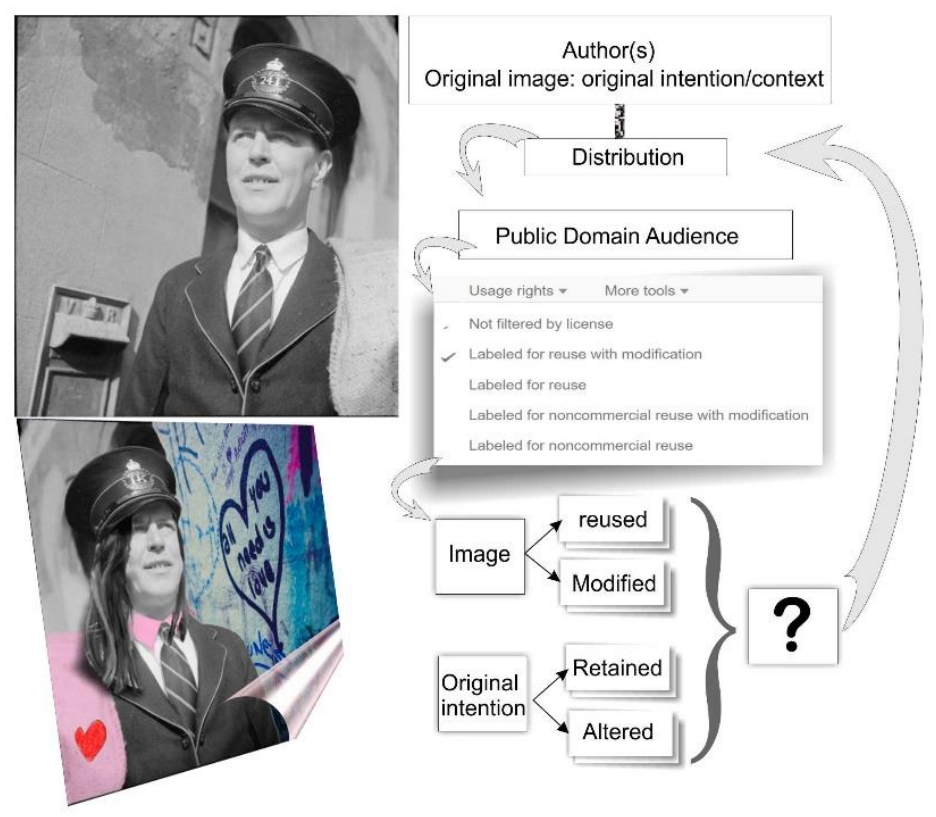

Figure 1. Postman image ${ }^{3}$

Easy availability of images in the public domain seems to facilitate indiscriminate secondary use. Members of the public feel a sense of entitlement to use or abuse such images by either altering their content or context (Lankshear and Knobel, 2007; Parry et al., 2017) — if indeed the original context is still accessible. This is where the danger of habit can create complacency, leading us to treat any image in the same way. Once a photograph appears in the public domain, all potential meanings belong to the spectator-cum-archivist-cum-author, whose intention may well be, as Baudrillard (1994) asserted, to ventilate, to manipulate, to circulate and make circulate. The image becomes an actor in anyone's possible plot. In the Google picture above, actors would include the person, clothes, body posture, profession, background, colour, etc. It is possible that this image may have complemented information about post office recruitment, but with time, a secondary use may have given it a different focus (Sontag, 2003). Later audiences may stop and consider some of the actors in the image in terms of how they differ from now rather than consider a potential position at the post office. Such activities are commonly found in educational settings. Children are often shown photos of past times in order to discuss historical aspects and make comparisons (Pegler-Gordon, 2006) which helps children notice and articulate differences and awareness. In this case, teachers become archivists and authors; leaving content intact but changing its original intention to 'documentary evidence' (Brink, 2000) which must, nonetheless, be done cautiously (Hållander, 2015). Journeying into the future the postman photograph has become another image in a sea of Google images, found under specific usage rights, as provided by Google Tools: 'Labelled for reuse with modification', thus finding its way into this article, which has nothing to do with postal recruitment or any type of job or past period in time. As a viewer-cum-author I use it merely as means to make a point completely unrelated to its original intention. I have slightly altered the image 
by adding other actors (colour, writing, a heart, hair, angles, etc.); photoshopping is common practice even in research (Jordan, 2014).

Many images appear (redistributed again) in the public domain whose veracity is suspect (i.e. fake news), and one wonders if with time, Google might treat certain images differently, perhaps by adding another label to their usage rights along the lines of, 'Unaltered image, labelled for non-commercial reuse, for self-reference contextualisation only'. Would photographs representing human distress fall under such a category? An image that can only be used in reference to itself; to its very subject as opposed to using it as a trigger to a discussion on say, suffering.

I'm not sure how far academics wrestle with these questions when looking for just the right image to accompany a point. What sways our decisions? Does space and time make a difference to the issue? Perhaps a picture of Jack the ripper's victims is a more acceptable resource to initiate discussions on victimhood than a photo of Vietnamese victims in a field, or of washed-up migrant bodies on a beach. I doubt this. But whatever our reasons for using such images in this way we need to be aware that we are treating them merely as means, and to reflect on the implications.

All these layers of interrelationships in past, present and future meanings photographs are given and the impact they can have matters because as lecturers, how we teach our students to see the representation of others, matters.

In our always at least partially visual public spheres, photographs and photography have repeatedly become the basis for significant 'civic negotiations' over resources and membership, rights and obligationsnegotiations that affect not only the contours of policy and the fortunes of politicians but more quotidian configurations of power, identity, agency, desire, hope, and fear (Reinhart, 2012, p. 34).

Easy participatory authorship, collaboration and distribution (Lankshear and Knobel, 2007), can make an author-cum-distributer out of anyone, or what the technology vernacular would generously call a 'creative' user. Indeed, it is difficult to escape it, which is why the narratives accompanying photographs matter (Sontag, 2003). However, although these narratives can teach us how to read certain images, how to listen to them, they can also teach us how to misunderstand them, how to objectify their subject. The political, social and cultural narratives played out through the use of some photographs need to be illuminated, particularly when image provenance is unknown. The moral response they invoke may be inevitable, but such response is most useful when in relation to what it means to use such images, not just as a response to having seen them.

\section{USING REPRESENTATIONS OF OTHER PEOPLE'S DISTRESS}

When we consider using an image whose provenance is unknown, it is apt to remember what Kant says in his Formula of Respect for Persons, also known as the Formula of Humanity. It states: 'Act in accordance with a maxim of ends that it can be a universal law for everyone (6:395; p157)' (Gregor, 1996, xviii). This sounds like a pertinent baseline calculation to any of our online interactions with others, who in many cases can literally be 'anybody'. The outcome of this calculation, however, will only be as good as our understanding of our own motives of use and the reach of its impact. Online 'others' usually come as a 'representation of others'. In the Formula of Respect for Persons, could the word 'persons' encompass the 'photographic 
representation' of those persons as well? And if these representations involve the distress of past or present vulnerable persons, then the precepts we use to act around them become critical and inextricably connected to the social and the political-lest we focus on the symptoms and not the causes. I will next present two scenarios that can help us explore some of these ideas further.

Bourdieu's original decision not to publish the many ethnographic documentary photographs he took during his time in Algeria, was born out of a sense of ultimate betrayal towards Their subject (Back, 2009). While interviewing the local bachelors, Bourdieu noted,

... I felt the sense of committing something like a betrayal-which led me to refuse to this day any re-publication of texts whose appearance in scholarly journals with small readerships protected them against ill intentioned or voyeuristic readings (Bourdieu, 2004a: 437, emphasis added) (Back, 2009, p. 476).

Bourdieu's decision may have protected the photographs from a non-scholarly readership, but Back doesn't comment on the power the scholarly readership has in the framing of actions and discussions around images with students. Bourdieu lifted the ban near the end of his life, and during an exhibition of these photographs at Goldsmiths College in London, a complaint was made about one of the images. A woman called its display unethical, in that it showed gratuitous suffering and that it was practically an image of child abuse, vulnerable to being re-abused. The complaint was taken seriously by Back,

There was something very disturbing and haunting about the image, in which the child looks as if to ask 'Why are you looking at me?' We debated whether or not to take the photograph down. Our intention was to use Bourdieu's photographic work to ask searching questions including whether there are places where a camera should never be pointed and whether there are some photographs that should not be taken. Was this photograph itself an instance of the symbolic violence that Bourdieu himself had so often criticised? Were we not also complicit through our commitment to show all the photographs? The answer is undoubtedly 'yes' and yet at the same time we wanted to open up such questions for debate and reflection: to censor the image would have been concealment (Back, 2009, p. 482).

... Reflecting with the benefit of hindsight, I feel personally, it was a photograph that should not have been shown (ibid., p. 483).

Despite this incident, Back does not spend a great deal of time in his paper reflecting on the issue of the showing of a photograph. His focus is towards the ethics of taking them. He reflects on two kinds of betrayal: towards the photographs' subjects, and in the ways the photographer gives himself 'away' in the very act of taking a picture, and then distributing it, betraying political, cultural and social ideologies. I would argue also, that a lecturer's decision to use such an image is a third betrayal: a betrayal towards the students whose future actions are guided by the lecturer's example.

Back enframed the photographs in the context of an exhibition, where viewers were invited to think but were not required to share their responses and were free to 
walk away. Many lecturers however use images to spark discussions among students who are not so free to walk away. Let us set out a second, not uncommon scenario:

Suppose you are a HE student in London taking a masters module on Advanced Counselling for PTSD victims. You are one of twenty students attending the first ever session. Near the end of the session, after a great deal of discussion on different approaches to counselling, the lecturer shows on the large interactive whiteboard, a colour image of the burnt-out Grenfell tower. You are asked to engage with this image for a few minutes, note down your impressions, and then share your thoughts with your classmates.

In what follows I attempt to untangle the three themes that constitute a vicious cycle in these scenarios. First, the relationship between the photographs and the narratives that treat them merely as means. Second, the ways in which this use leads to the objectification of those represented in the images. Third, how, by such treatment, we model the objectification of the vulnerable communities represented to our students, thus sustaining hegemony.

I would argue that for an awareness of female genital mutilation (FGM) or a discussion about counselling one does not need a shocking photograph. It adds no value unless shocking the audience to some effect is part of the activity, or unless if forms part of a forensic study. '[Harrowing photographs] are not much help if the task is to understand. Narratives can make us understand. Photographs do something else: they haunt us' (Sontag, 2003, p. 80). Although I would agree with this statement I do so only in part. Firstly, whose 'narrative' do we accept? By 'narrative' Sontag refers to the whys and hows of a represented subject, in the way that Hållander supports, and yes, discussions can make us understand the event in some particular way if that is what we want. But the image itself carries its own narrative which is aesthetic in nature (Shirm, 2015; Roberts, 2010). The photograph may well haunt us because it makes us understand or 'see' a different narrative. It may also add an emotional charge that augments, detracts from or skews a narrative. If this is what a lecturer intends then it needs to be made clear to the students.

A point in case is Judith Butler's powerful arguments about the politics of national mourning in relation to the events of 9/11 (2004), and about torture and the use of photography in the Abu Ghraib images (2007). Both these events have powerful image representations, yet, no images were deemed necessary to lend weight to her arguments. Hers is a legitimate narrative that does not revolve around the images (even in her attempt to describe them) so much as what 'enframes' them socially and politically as events which have 'currency' in both its meanings. Her argument makes us think and has epistemic value.

Legitimacy of use may be perceived to fall under the umbrella of 'the good cause', like bringing awareness, enhancing student knowledge, means to epistemic virtue, etc. However, in our second scenario, can a photograph of the burnt-out Grenfell tower, even with no persons in sight, be constructed as a valid educational resource, to be academically gazed at in the name of a discussion on a different subject altogether, however benign? Can such images ever be used merely as means? Discussions on crime documentary photographs (Möller, 2009) as well as on medical photography (Csengei, 2003), use the idea of knowledge advancement and the ultimate social benefit as a legitimate reason for 'seeing' photographs of pain. For more reflective practitioners however, things are never that simple.

It is immaterial whether the patient is identifiable or not, because, it is consent to photography that is the issue ... the patient or the deceased 
have become objectified and merely a source of teaching material or, alarmingly, a curiosity. ... from the Kantian perspective any use of the material is demonstrably a violation of a patient's right not to be objectified (Berle, 2008, p. 90).

Issues of consent may seem easier to ignore when the provenance of an image is unknown. These questions are part of the narrative of use. One might think that, accompanying such images by YouTube clips or a news channel interviewing one of the tragedy's survivors, may count as a form of 'borrowed' consent. During interviews however, victims only consent to inform the viewers about their plight in the hope that somebody will do something to resolve their plight. Although a victim would possibly share the lecturer's ends of preparing the next generation of counsellors, and thus possibly give consent to the use of the video clip, the photograph itself remains apart, resisting instrumentalisation by carrying its own narrative, ignored at the users' peril. Such an image is beyond the victims and survivors' remit; it is an unfettered protagonist, with too much of our (in)humanity in it. It has become, like many other such photographs of our time, a portrait of humanity gone astray.

In Back's case, he does not ponder why Bourdieu lifted the long-held ban on his images. The proximity of an event (local, recent) may make a difference to the narratives we consider around consent. Did Bourdieu perhaps feel that time had erased the danger of betrayal? Morally speaking, it begs the question whether the lifting of this ban really was up to Bourdieu. Could he not have perhaps, sought advice from Algerian representatives? The 'represented' which was not just a girl but a whole 'betrayed' vulnerable community, seem to have 'passed away' in Bourdieu's mind too. Back was right to have regretted its use in such a forum, and wise to open up the issue for academic discussion.

Although vulnerability is universally present in various forms, rarely is it aggregated in visibly 'photographable' form as in the case of poverty; the sociopolitical aspects cannot escape debates involving vulnerable communities.

The extent to which vulnerable communities are represented in person in the academic forum where such images are often used is not encouraging. This is where politics matter above the moral indignation. Are we, lecturers, somehow an instance of the power vulnerable communities have to deal with? Perhaps 'scholars' and 'academics' are viewed in a similar light to 'politicians' in the way they can approach others' distress. It may be that, for the vulnerable community of Grenfell Tower, academics are perceived as connected - by social standing — with the Royal Borough of Kensington and Chelsea council. I dread to think that we may be seen as a kind of Dead Third (Gerson, 2009), a segment of society in a position of access and relative power who should have known, should know better but are powerless to help, or worse, may perpetuate the objectification, injury and injustice, through, for instance, the careless use of sensitive photographs. 


\section{WHERE IS THE BROKEN GLASS?}

Some injustices are more difficult to articulate than others when their photographic representation has no perpetrators who are easily identifiable by common consent. Circumstances endow these perpetrators with a 'slippery moral surface produced by their roles or offices' (Nagel, 1979, p. 75). If injustices are not acknowledged in the public arena for what they are, then we, by a careless use of images representing such events and communities, run the risk of unintentionally re-inflicting those injustices on those represented and thus consolidating their objectification by the observer (Reinhardt, 2012).

The fact that many survivors feel that justice has not been done in the event of the Grenfell fire is an uncomfortable bench on which to sit for any discussion involving It. Caution around these images is paramount, for in the act of use we are training others into our ways of knowing and discussing phenomena (Hållander, 2015). In his essay 'Art and Mass Culture' Horkheimer (1975) alludes to a view of knowledge that challenges rather than describes or looks to the essence of being, 'Knowledge really concerned with values does not look to higher realms. It rather tries to penetrate the cultural pretences of its time, in order to distinguish the features of a frustrated humanity. Values are to be disclosed by uncovering the historical practice that destroys them' (Horkheimer, 1975, p, 286). In this light, a photograph of the burnt-out tower cannot be viewed as a simple representation of human distress, nor its misuse as a mere unfortunate act in need of reprobation. These actions can reify the system that supports them if left critically unchallenged. I do not argue for the banishment of such images in educational contexts, but for an explicit discussion on what using them implies. Gottesman (2016) highlights this point as he discusses Freire's Pedagogy of the Oppressed, placing his work as part of Freire's ideological narrative. Gottesman says,

... in Freire's oft cited definition of 'praxis: reflection and action upon the world in order to transform it' (p. 36). ... praxis, which he often referred to as a 'critical intervention' must take place between the oppressed and those in solidarity with the oppressed. This is because those of the oppressor class who are in solidarity with the oppressed are uniquely in a position to help the oppressed recognize the objective reality of dehumanization. Thus, although only the oppressed can most fully understand their oppressor and, therefore, must be the historical force of their own liberation, dehumanization is so internalized among the oppressed that it is difficult for [them] to recognize that dehumanization is not an historical and unchangeable fact (Gottesman, 2016, p.13).

This is critical when it comes to using photographs representing the distress of vulnerable others, particularly when those others are not included in the discussion, and even more so when those discussions are controlled by a different, more affluent community. This act can render the vulnerable powerless.

The image of the burnt-out tower does not necessarily represent 'another community' but what may simultaneously separate and join us to it, the abject, be that guilt, shame, impotence or even denial of what lurks under and around the photograph. In the opening quote to this paper, what horrifies Dorian Gray is not the portrait itself but the narrative it calls forth which no words alone can. The photograph 
of the Grenfell fire does not uncover a vulnerable community so much as the horror behind the horror in front of the horror. The role of all protagonists is intersected and called forth: to be caused by a failing regulatory system; to be captured by commodity, to be dissected by scholars (we dissect what is lifeless and powerless).

It takes effort to do things in new ways. However, bringing awareness into our use of images is achievable. We can start by questioning how, or indeed whether, our day-to-day decisions support the ideologies we claim to stand by (Small, 2001). Giroux, explains Gottesman, proposes the kind of critical pedagogy that makes us pay attention to the not-insignificant details that form our practice, by examining all areas, from the resources, form and content used by teachers to, 'the discourse and practices of even those who appear to have penetrated its logic' (Giroux, 1981, p. 29). This is needed in HE just as much as in schools to which Giroux referred.

How might we, as a scholarly community, begin to learn to see and use photographs of vulnerable communities in distress differently? The point of view given by the angle of a shot or accompanying narrative does not necessarily capture what makes the image what it is. A first viewing of such images does not resist the appeal to humanity and identity - whether our own or that of others - or to universal values, but this first response is not a response as such, but rather a continuing construction of the event and its subject. Derrida, comments Masó, urges us to think about certain images which involve identity and communities: to take a closer look at what surrounds the practice of an image and see where differences between communities really lie, invisibly and thus reinforced; to see that the outcome of a response such as solidarity does not erase difference but only hides it from view; that in those 'unseen' acts lurking outside the frame hides the real state of things; what I would call a 'hidden' protagonist. Commenting on Frédéric Brenner's Diaspora, referring to a 1944 photograph which 'shows solidarity' following an antisemitic incident in Billings, Montana, Derrida writes,

Never forget; never forget to see that through which you see the apparent diaphanous element of visibility. Here that element is broken. The photograph is taken-in a moment you will know why-through the broken glass of a window (Masó, 2014, p. 208).

It is the unphotographable angle of the whys and hows of a violent act (a stone thrown through a window which knocks down a menorah): the oppression on a 'different' community, which is unveiled by looking towards the lens of a camera as opposed to just through it. Focusing only on the photographable act of a whole town holding up menorahs in solidarity, will hide rather than address difference and injustice. Minorities are often dissolved into majorities in the attempt to erase what makes them different, so that we may have the illusion of solidarity and 'feeling together' and 'standing by and for one another'. But such identifications, though loud are ephemeral and ineffective in the long term. A photograph, and the use of a photograph consolidating such a state should make us stop and think again. Where is the real broken glass?

In the case of the use of Bourdieu and the Grenfell Tower photographs, I would argue the 'break' is caused by the sense of one community oppressing an economically vulnerable other; a second break occurs in our continuing oppression of the vulnerable through the objectification of the photographic representation of their distress. 


\section{CONCLUSION}

A careless use of images representing human distress unveils a hidden protagonist in the narrative of use: the hegemony sustained through the socio-political framing of the photograph's subject. This unveiling only happens when we pay attention to it; when we morally consider the treatment of such images.

The secondary use of such photographs should bring us to reconsider the Kantian precept. In this day and age, we should not only treat others, but also the photographic representation of others, always as ends and never merely as means. It is in the way we use the representation of others' distress, that the concealed narratives towards vulnerable others are often taught, learned, negotiated and enacted. These are moral considerations to help us reflect on our own practice. Situations of moral concern which, although caused and sustained by our pedagogical, social and political stance, can be addressed likewise.

Engaging in a critical pedagogy might take us some way towards a more careful approach to the use of photographs. In practice, it should not be a question of whether one should or should not use such images, but rather, what it means to use those images in the way we are contemplating. Appealing to a 'good cause' when using the photographic distress of a vulnerable community cannot be done at the expense of its further objectification. As educators we need to challenge our own ways of knowing and seeing photographic resources with our students, lest we do the complete opposite of Freire's intention: sustain hegemony by supporting the oppressor's perspective and aperture. It is this aperture and choice of focus which Derrida explores in his commentary and dares us to look at; to never forget to look at; and to interrogate. This is important because the photographic representation of others' distress often encompasses vulnerable communities. In any secondary use of such images we need to include those communities in control of the academic discourse around their photographic representation. This act may render such secondary use impossible, for which community would agree to have their distress used in such ways? As such, some photographs are beyond the remit of even victims' or survivors' consent; their representational narrative too strong to bend to interpretation and secondary use. ${ }^{4}$

Correspondence: Paula Alexandra Ambrossi, Institute of Education, University College London, 20 Bedford Way, London, WC1H 0AL.

Email: p.ambrossi@ucl.ac.uk

\section{NOTES}

1. By 'vulnerable community' — and I do not mean necessarily powerless - I refer to groups of persons living in low socio-economic circumstances, often in receipt of government benefits and social housing.

2. According to official figures, 72 people lost their lives.

3. Postman Photograph (1942), Ex-postman Delivers the Guns. Merchant Navy Training in Britain. Copyright expired as the photograph was taken prior to 1 June 1957. Available online at: https://commons.wikimedia.org/wiki/File:Ex- 
postman Delivers the Guns- Merchant Navy Training in Britain, 1942 D8006.jpg

(Accessed: 28 June 2019).

4. I thank the Philosophy Department at the Institute of Education for the opportunity to engage in, and inspiration to contribute to, philosophic dialogue.

\section{REFERENCES}

Ahn, P. (2017) Using Photographs in Interpreting Cultural and Symbolic Meaning: A Reflection on Photographs of the Korean Association for Government Accounting. In press, http://dx.doi.org/10.1016/j.accfor.2017.08.002 [Accessed on 27 ${ }^{\text {th }}$ February, 2018]

Azoulay, A. (2010) What is a Photograph? What is Photography? Philosophy of Photography, 1.1, pp. 9-13.

Back, L. (2009) Portrayal and Betrayal: Bourdieu, Photography and Sociological Life. The Sociological Review, 57.3, pp. 471-490

Baudrillard, J. (1994) The Beaubourg Effect: Implosion and Deterrence, in: trans. S. F. Glaser, Simulacra and Simulation (XXXX, University of Michigan Press).

Berle, I. (2008) Clinical Photography and Patient Rights: The Need for Orthopraxy. Journal of Medical Ethics, 34.2, pp. 89-92.

Brink, C. (2000) Secular Icons: Looking at Photographs from Nazi Concentration Camps. History and Memory Journal, 12.1, pp. 135-150.

Butler, J. (2004) Violence, Mourning, Politics, in: XXXXXXX Precarious Life: The Powers of Mourning and Violence (London, Verso).

Chalfen, R. (2009) 'It's Only a Picture': Sexting, 'Smutty' Snapshots and Felony Charges. Visual Studies, 24.3, pp. 258-268.

Csengei I. (2003) Sensibility in Dissection: Affect, Aesthetics, and the Eighteenth-Century Body In Pain. Hungarian Journal of English and American Studies, 9.2, xxxxx.

Fenton, L. (2009) Representations of Voodoo: The History and Influence of Haitian Vodou within the Cultural Productions of Britain and America since 1850. Warwick.

Gerson, S. (2009) When the Third is Dead: Memory, Mourning, and Witnessing in the Aftermath of the Holocaust. International Journal of Psychoanalysis, Volume: 90 Issue: 6 Page: 1341 -1357

Gregor, M., (1996) Kant: The Metaphysics of Morals (Cambridge, Cambridge University Press).

Grønstad, A. and Gustafsso, H. (2012) Ethics and Images of Pain (XXXXXX, Routledge).

Hållander, M. (2015) Voices from the Past: On Representations of Suffering in Education. Ethics and Education, 10.2, pp. 175-185.

Horkheimer, M. and Aronowitz, S. (1975) Art and Mass Culture, in: trans. M. J. O'Connell Critical Theory: Selected Essays (1st edition) (New York, Continuum Publishing Corporation).

Kerstein, S. (2009) Treating Others Merely as Means. Utilitas, 21.2, pp. 163-180. 
Langmann, S. and Pick, D. (2014) Dignity and Ethics in Research Photography. International Journal of Social Research Methodology, 17.6, pp. 709-721.

Lankshear, C. and Knobel, M. (2007) Sampling 'the New' in New Literacies, in: Knobel, M. and Lankshea, C. A New Literacies Sampler (New York: Peter Lang) pp. 1-23.

Lyons, M. (2015) Safe Spaces and Comfort Zones: Confronting the Brutal Facts of History Can Be Difficult, in: History Today, http://www.historytoday.com/mathew-lyons/safe-spaces-andcomfort-zones [Accessed on $10^{\text {th }}$ February, 2018]

Masó, J. (2014) What Does Difference Have to Do with Community? Derrida's Diacritic Difference. Critical Studies; Leiden, 37, pp. 203-216,249.

Möller, F. (2009) The Looking/Not Looking Dilemma. Review of International Studies, 35, pp. 781794.

Nagel, T. (1979) Mortal Questions (Cambridge, Cambridge University Press).

O'Neill, O. (1989) Constructions of Reason (Cambridge, Cambridge University Press).

Parry, B., Burnett, C. and Merchant, G. (2017) Literacy, Media, Technology, Past, Present and Future (London, Bloomsbury Academic).

Pegler-Gordon, A. (2006) Seeing Images in History, History and Media, in American Historical Association

https://www.historians.org/publications-and-directories/perspectives-on-history/february-2006/seeingimages-in-history [Accessed on $10^{\text {th }}$ February, 2018]

Reinhardt, M. (2012) Painful Photographs: From the Ethics of Spectatorship to Visual Politics, in: Gronstad and Gustafsson (eds) Ethics and Images of Pain (XXXX, Routledge).

Small, R. (2001) Codes Are Not Enough: What Philosophy Can Contribute to the Ethics of Educational Research. Journal of Philosophy of Education, 35.3, pp. 387-406.

Sontag, S. (2003) Regarding the Pain of Others (New York, Farrar, Straus and Giroux).

Wilde, O. (1891) The Picture of Dorian Gray, online version, https://www.gutenberg.org/files/174/174h/174-h.htm (Last accessed: 29November 2017).

Zylinska, J. (2015) The Creative Power of Nonhuman Photography, in: M. Elo and M. Karo with M. Goodwin (eds), Photographic Powers (Helsinki, Aalto University) pp. 132-154. 